Vol. 5, No. 1, 2019

Ihor Kuzio ${ }^{1}$, Bogdan Vasyliv ${ }^{2}$, Vitaliy Korendiy ${ }^{3}$, Volodymyr Borovets ${ }^{4}$, Viktoriya Podhurska ${ }^{5}$

1. Department of Mechanics and Automation Engineering, Lviv Polytechnic National University, Ukraine, Lviv,

S. Bandery street 12, E-mail: Ihor.V.Kuzo@lpnu.ua

2. Department of Mechanics and Automation Engineering, Lviv Polytechnic National University, Ukraine, Lviv,

S. Bandery street 12, E-mail: mechengin1111@gmail.com

3. Department of Mechanics and Automation Engineering, Lviv Polytechnic National University, Ukraine, Lviv,

S. Bandery street 12, E-mail: vitaliy.nulp@gmail.com

4. Department of Mechanics and Automation Engineering, Lviv Polytechnic National University, Ukraine, Lviv,

S. Bandery street 12, E-mail: volbor1@gmail.com

5. Department of Structural Fracture Mechanics of Materials, Karpenko Physico-Mechanical Institute, Ukraine, Lviv, Naukova street 5, E-mail: podhurskavika@gmail.com

\title{
SUBSTANTIATION OF THE SHAPE OF A SOLID OXIDE FUEL CELL ANODE USING THE STRESS-STRAIN AND SHAPE-DEPENDENT CRACK DECELERATION APPROACHES
}

\author{
Received: January 16, 2019 / Revised: March 14, 2019 / Accepted: June 26, 2019
}

\section{(C) Kuzio I., Vasyliv B., Korendiy V., Borovets V., Podhurska V., 2019}

\begin{abstract}
Stress and strain distributions in the YSZ-NiO spheroidal shape anode-substrate for a solid oxide fuel cell (SOFC) under pressure of operating environment were calculated using the finite element analysis. The features were then compared with ones of the cylindrical shape anode. The radii ranges for the cylindrical and spheroidal (segments of a sphere) parts of the anode ensuring its improved deformation resistance and more uniform stress distribution were suggested.

Based on the calculations, an anode of the cylindrical shape with top and bottom convex surfaces (a spheroidal shape anode), with the spheroid to cylinder radii ratio $R / R_{c}$ in the range from 5 to 20 is suggested. Its specific volume $V / S_{c}$ is in the range from 1 to $2.5 \mathrm{~mm}$. The stresses in the most dangerous areas (i. e. along the axis and the closed-loop fixing) and maximum strain, caused by external gas pressure on the anode working surface, are decreased by $10-30 \%$ and $20-40 \%$ respectively as compared to an anode of the cylindrical shape of the same radius and volume features. This increases the lifetime of a solid oxide fuel cell. A three-dimensional curve of intersection of the surfaces of stress distribution in the anode along its axis and the closed-loop fixing was approximated which displays the values of balanced stresses depending on $V / V_{c}$ and $R / R_{c}$ parameters. Also, the advantage of the spheroid shaped SOFC anode-substrate over conventional flat one was substantiated using a shape-dependent crack deceleration approach.
\end{abstract}

Keywords: solid oxide fuel cell, cylindrical and spheroidal shape anodes, finite element analysis, stress and strain distributions, shape-dependent crack deceleration approach, lifetime.

\section{Introduction}

A solid oxide fuel cell (SOFC) is an electrochemical conversion device that produces electricity directly from oxidizing a fuel. Fuel cells are characterized by their electrolyte material; the SOFC has a solid oxide (ceramic) electrolyte. The advantages of this class of fuel cells include high efficiency, longterm stability, fuel flexibility, low emissions, and relatively low cost. The largest disadvantage is the high operating temperature which results in longer start-up times and mechanical and chemical compatibility issues.

Among the up-to-date versions of the SOFC design, the anode supported one prevails which consists of the thick anode substrate layer and comparatively thin electrolyte and cathode layers. A porous cermet 


\section{Ihor Kuzio, Bogdan Vasyliv, Vitaliy Korendiy, Volodymyr Borovets, Viktoriya Podhurska}

consisting of two solid phases (nickel one and zirconia stabilized with scandia and ceria (or with yttria), i.e. ScCeSZ-Ni or YSZ-Ni) and pores, is widely used as anode material for a SOFC [1] - [4]. To reach required electrical conductivity of as-sintered $\mathrm{ScCeSZ}-\mathrm{NiO}$ or $\mathrm{YSZ}-\mathrm{NiO}$ ceramic anode, it is subjected to a reduction in a hydrogenous environment at high temperature (usually a few hundred degrees Celsius). Due to the reduction of $\mathrm{NiO}$ particles a nickel network is formed in a ceramic (YSZ) skeleton of the anode.

\section{Problem Statement}

In order to improve a lifetime of a SOFC and to lower the cost of electricity that it produces, researchers work to optimize the structure of its components to prevent degradation of the physical and mechanical properties and improve the structure of the SOFC as layered macrocomposite [5] - [9]. For this reason, elementary (single) SOFCs of various geometrical shapes (from flat to cylindrical) have been developed.

\section{Review of Modern Information Sources on the Subject of the Paper}

The operating surface area of an anode of tubular shape [10] is of maximum possible value from the geometrical and structural points of view. However, the length of a tubular SOFC is limited by the stresses which occurred at sealing the environment supply system, as well as caused by the environment pressure.

An anode of truncated cone shape [11] has a large operating surface area, characterized by a high value of the ratio of surface area to volume of the anode, which is however lower by $20-25 \%$ than for the anode of tubular shape. Its shape provides connecting the battery of elementary SOFCs in such a way that each next cell by its wider part is imposed on the narrower part of the previous cell. However, to ensure a large operating surface area, the angle at the top corner of the cone should be small (2-10 degrees). In this case, substantial tensile stress arises in a wider part of each cell during the operation, causing initiation of a network of microcracks at the cell edge that reduces its lifetime.

A flat anode of rectangular shape with a plane work surface [12] is cheaper to manufacture as compared to the mentioned above variants because of using a relatively cheap technology of type casting. In the same way, thin electrolyte and cathode layers are formed on the anode-substrate. However, an operating surface area of such a SOFC is limited because of the limited thickness of the anode and the stresses arising when assembling elementary fuel cells in a stack. These stresses are not distributed uniformly [13].

Another variant of a flat anode-substrate with a plane work surface is of a round shape (cylindrical anode) [14]. Due to the assembling of elementary fuel cells in a stack, axially symmetric stresses arise in the anode-substrate. However, the diameter of the elementary fuel cell and, consequently, its operating surface area is limited by the thickness of the anode and the ultimate stress along the axis of the cell due to this consolidation scheme. So the cylindrical anode does not provide the required deformation resistance and, consequently, the required lifetime of a SOFC. These factors affect the cost of electricity that it produces, and fuel cell performance per unit volume of the anode.

A new improved shape of a SOFC anode has been proposed recently [15]. The anode of such spheroidal shape provides improved resistance to deformation.

\section{Objectives and Problems of Research}

The purpose of this work is to determine radii ranges for cylindrical and convex (spheroidal) parts of the SOFC spheroidal shape anode based on stress and strain parameters calculated, and substantiate the anode potential to withstand deformation, stress gradient, and crack growth under operational conditions.

\section{Results and Discussion}

Traditionally, the anode can be composed of a mixture of ScCeSZ powders (cubic structured zirconia $\mathrm{ZrO}_{2}$ stabilized with $10 \mathrm{~mol} \% \mathrm{Sc}_{2} \mathrm{O}_{3}$ and $1 \mathrm{~mol} \% \mathrm{CeO}_{2}$ ) with addition of $20-50 \mathrm{wt} \% \mathrm{NiO}$, or also can be composed of a mixture of $\mathrm{YSZ}$ powders (cubic structured zirconia $\mathrm{ZrO}_{2}$ stabilized with $8 \mathrm{~mol} \% \mathrm{Y}_{2} \mathrm{O}_{3}$ ) with addition of $20-50 \mathrm{wt} \% \mathrm{NiO}$. The mixture is compressed under pressure of $16-20 \mathrm{MPa}$ at a temperature of $20{ }^{\circ} \mathrm{C}$ in a cylindrical mold with the concave bottom of the spheroidal shape, with a punch of the same 


\section{Substantiation of the Shape of a Solid Oxide Fuel Cell Anode using the Stress-Strain and ...}

spheroidal shape of its contacting surface. As a result, a cylinder shape pressed body with top and bottom convex surfaces is formed (called a spheroidal shape anode). During 1-4 h of exposure at $800-1250{ }^{\circ} \mathrm{C}$ preliminary annealing of the body is performed which is followed by shrinkage and pore formation, and integrated material structure is formed. Finally, the body is sintered at $1350-1450{ }^{\circ} \mathrm{C}$ in air or inert gas during $2-5 \mathrm{~h}$.

Stress and strain parameters of the anodes of the cylindrical and proposed spheroidal shapes (Fig. 1) were calculated by finite element analysis using software for calculating three-dimensional tasks Mechanical Desktop 6 Power Pack. Initial conditions were as follows:

Material of $\mathrm{ZrO}_{2}-\mathrm{Y}_{2} \mathrm{O}_{3}-\mathrm{Ni}$ system; average value of ultimate fracture stress $\sigma_{f}=110 \mathrm{MPa}$; Young's modulus $E=1.5 \cdot 10^{5} \mathrm{MPa}$; Poisson's coefficient $v=0.3$; fixing pressure $n=1 \mathrm{MPa}$ along the closed-loop fixing of inner radius $R_{p}=10.5 \mathrm{~mm}$; external gas pressure $p=1 \mathrm{MPa}$ on the anode working surface; radius of the cylindrical part of anodes $R_{c}=12 \mathrm{~mm}$; spheroid radii, $R$, were 240,60 , and $36 \mathrm{~mm}$ respectively.

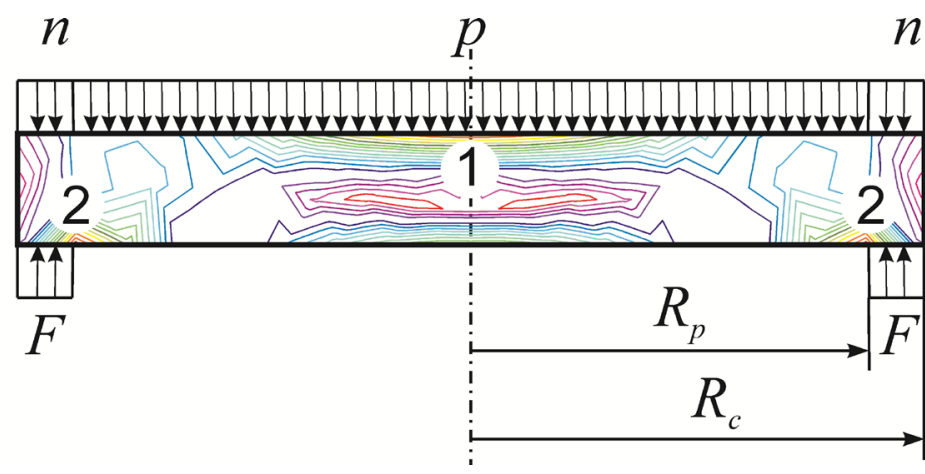

$n$

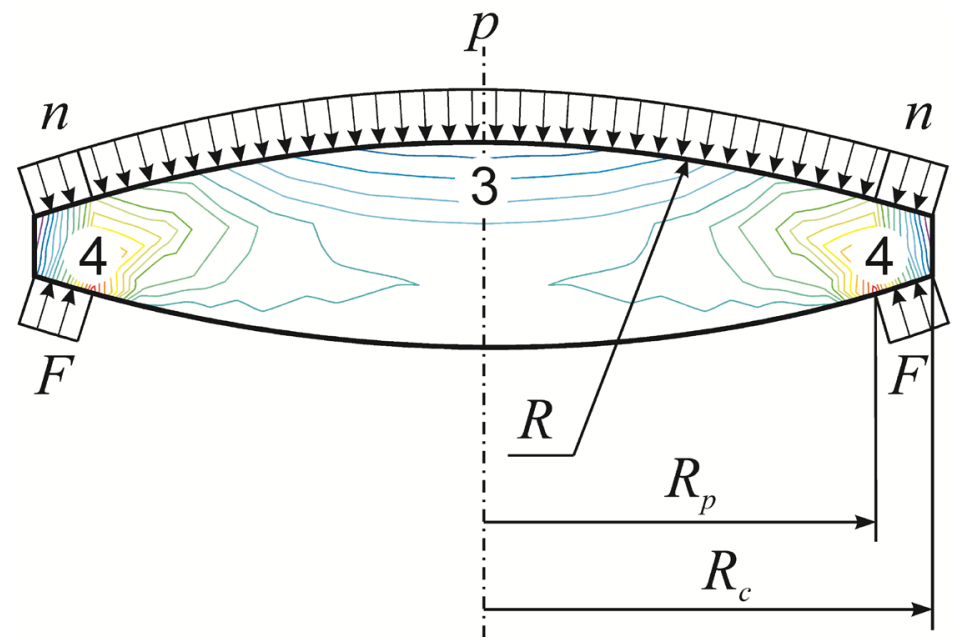

Fig. 1. Diagrams of application of fixing pressure, $n$, along the closed-loop fixing of inner radius, $R_{p}$, external gas pressure, $p$, on the anode working area, reaction force, $F$, along the closed-loop fixing, stress distribution, $\sigma$, along the axis (items 1 and 3 ) and the closed-loop fixing ( 2 and 4 ) in the anode of a cylinder radius, $R_{c}$, with (a) parallel working surfaces and (b) convex ones of a spheroid radius, $\mathrm{R}$

To compare stress and strain features of the anodes of the cylindrical and spheroidal shapes, the following parameters were calculated:

- volume $V_{c}$ of an anode of the cylindrical shape

$$
V_{c}=\pi \cdot R_{c}^{2} \cdot h,
$$

where $h$ is a height of a cylinder;

- volume $V_{s}$ of two convex parts (spherical caps) of an anode of spheroidal shape

$$
V_{s}=\frac{2}{3} \pi \cdot H^{2} \cdot(3 \cdot R-H),
$$

where $H$ is a height of a convex part (spherical cap) of the anode; 


\section{Ihor Kuzio, Bogdan Vasyliv, Vitaliy Korendiy, Volodymyr Borovets, Viktoriya Podhurska}

- volume $V$ of an anode of spheroidal shape

$$
V=\pi \cdot R_{c}^{2} \cdot h+\frac{2}{3} \pi \cdot H^{2} \cdot(3 \cdot R-H) ;
$$

- area $S_{c}$ of the base of the cylindrical part of the anode

$$
S_{c}=\pi \cdot R_{c}^{2}
$$

- ratios $V / S_{c}$ and $V_{c} / S_{c}$;

- surface area increment $\Delta S$ (in \%) of an anode of a spheroidal shape

$$
\Delta S=100 \cdot\left(\frac{2 \cdot R \cdot H}{R_{c}^{2}}-1\right) ;
$$

- ratio $V / V_{c}$ of the spheroidal shape anode volume to the volume of an anode of the cylindrical shape;

- ratio $V / V_{c l}$ of the spheroidal shape anode volume to the volume of an anode of the cylindrical shape, where $V_{c l}=452 \mathrm{~mm}^{3}$ is the calculated volume of the cylindrical anode of radius $R_{c}=12 \mathrm{~mm}$ and of height $1 \mathrm{~mm}$ fabricated for industrial applications [7].

The range of values of $R / R_{c}$ ratio from 20 to 5 corresponds to a noticeable increment of anode surface area $\Delta S$ (up to $1 \%$, see Fig. 2). For this range at little working surface convexity, the ratio $V / V_{c l}$ is small (from 1.31 to 2.20). For the $R / R_{c}$ range from 3.5 to 5 increment of anode surface area $\Delta S$ is from 1 to $2 \%$ but a steep increase of anode volume occurs due to the excessive convexity ( $V / V_{c l}$ from 2.20 to $2.75)$, that does not provide the conditions for reactions to be passed in the fuel cell.

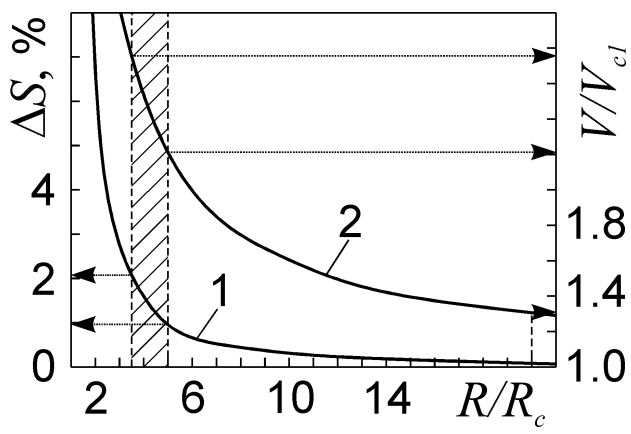

Fig. 2. A graph of calculated values of the area increment, $\Delta \mathrm{S}$, of a spheroidal shape anode (curve 1, an ordinate axis is on the left) and the ratio $\mathrm{V} / \mathrm{V}_{\mathrm{cl}}$ of the anode volume to the volume of the in-production cylindrical shape anode of a radius of $12 \mathrm{~mm}$ and of $1 \mathrm{~mm}$ thickness (curve 2, an ordinate axis is on the right) depending on the spheroid to cylinder radii ratio, $R / R_{c}$

The volumes $V$ and $V_{c}$, the area $S_{c}$, and $V / S_{c}$ ratio were calculated as functions of parameters $R, R_{c}$ $\left(R_{c}=12 \mathrm{~mm}\right)$ and variable anode height (its increment step was $\left.0.5 \mathrm{~mm}\right)$. For each partial case, the stress distribution and maximum strain were calculated by finite element analysis. Then the stresses in the most dangerous areas (i.e. along the axis (items 1 and 3, see Fig. 1) and the closed-loop fixing (2 and 4)) and maximum strain, $\varepsilon_{\max }$, along the axis vs $V / S_{c}$ ratio dependences were plotted (Fig. 3).

The dependences show that for an anode of the cylindrical shape the stresses along the axis are higher than ones along the closed-loop fixing (Fig. 3a, curve 1 contrary to curve 2). In contrast to this, for an anode of spheroidal shape even of little convexity $\left(R / R_{c}=20\right)$ the stresses along the axis and the closed-loop fixing, caused by external gas pressure on the anode working surface, are already balanced at the value of $V / S_{c}$ over $1.5 \mathrm{~mm}$ (Fig. 3a, curves 3 and 4), and the maximum strain is decreased by $10-30 \%$ as compared to an anode of the cylindrical shape (Fig. 3b, curve 10 contrary to curve 9).

For an anode of spheroidal shape with the ratios of $R / R_{c}$ in the range from 5 to 20 and of $V / S_{c}$ from 1 to $2.5 \mathrm{~mm}$ the stresses in the most dangerous areas (i.e. along the axis (items 1 and 3, see Fig. 1) and the closed-loop fixing (2 and 4)) and the maximum strain, caused by external gas pressure on the anode working surface, are decreased by $10-30 \%$ and $20-40 \%$ respectively as compared to an anode of the cylindrical shape of the same radius and volume features.

Based on the FEA calculations performed for spheroidal anodes with $R_{c}=12 \mathrm{~mm}$ and various values of $R$ (Fig. 4), the surfaces of stress distribution along their axes and closed-loop fixing were plotted. As a 


\section{Substantiation of the Shape of a Solid Oxide Fuel Cell Anode using the Stress-Strain and ...}

result of the graphic intersection of these surfaces, a three-dimensional curve was created (Fig. 4, surfaces 1 and 2 respectively, and curve 3). The curve displays the values of balanced stresses depending on $V / V_{c}$ and $R / R_{c}$ parameters. A domain of this curve was also defined.

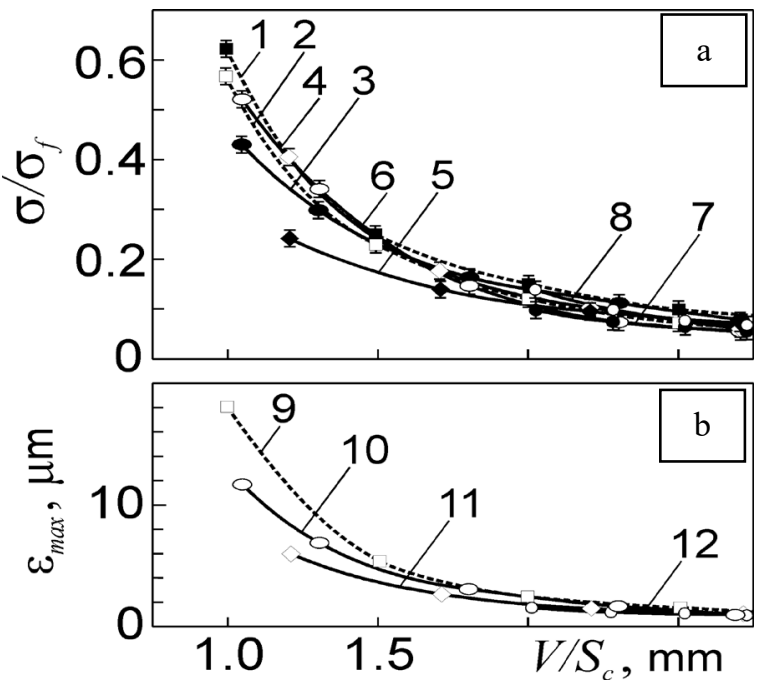

Fig. 3. Change in the values of (a) the ordinary to fracture stresses ratio, $\sigma / \sigma_{\mathrm{f}}$, along the axis (curves $1,3,5$, and 7$)$ and closed-loop fixing $(2,4,6$, and 8$)$ as well as (b) maximum strain, $\varepsilon_{\max }$, along the axis (9-12) caused by fixing pressure and external gas pressure on the anode working surface which are calculated using the finite element analysis, depending on the anode volume to its cylinder base area ratio, $\mathrm{V} / \mathrm{S}_{\mathrm{c}}$, for cylindrical shape anodes with parallel (curves 1, 2, and 9) and spheroidal working surfaces having the spheroid to cylinder radii ratio, $\mathrm{R} / \mathrm{R}_{\mathrm{c}}$, of 20 (curves 3,4 , and 10$), 5(5,6$, and 11 ), and $3(7,8$, and 12$)$ respectively

Projections of the curve on the coordinate planes $\left[V / V_{c} ; R / R_{c}\right],\left[\sigma / \sigma_{f} ; R / R_{c}\right]$, and $\left[\sigma / \sigma_{f} ; V / V_{c}\right]$ were approximated by the corresponding lines (Fig. 4, curves 3', 3', and 3',' respectively). Curve 3 ' for the ranges $0.065<\left(\sigma / \sigma_{f}\right)<0.460,1.20<\left(V / V_{c}\right)<1.58$, and $10<\left(R / R_{c}\right)<32$ was described by an equation:

$$
\begin{gathered}
V / V_{c}=0.00000547 \cdot\left(R / R_{c}\right)^{5}-0.0005109 \cdot\left(R / R_{c}\right)^{4}+0.01829 \cdot\left(R / R_{c}\right)^{3}- \\
-0.313 \cdot\left(R / R_{c}\right)^{2}+2.525 \cdot\left(R / R_{c}\right)-6.1085 .
\end{gathered}
$$

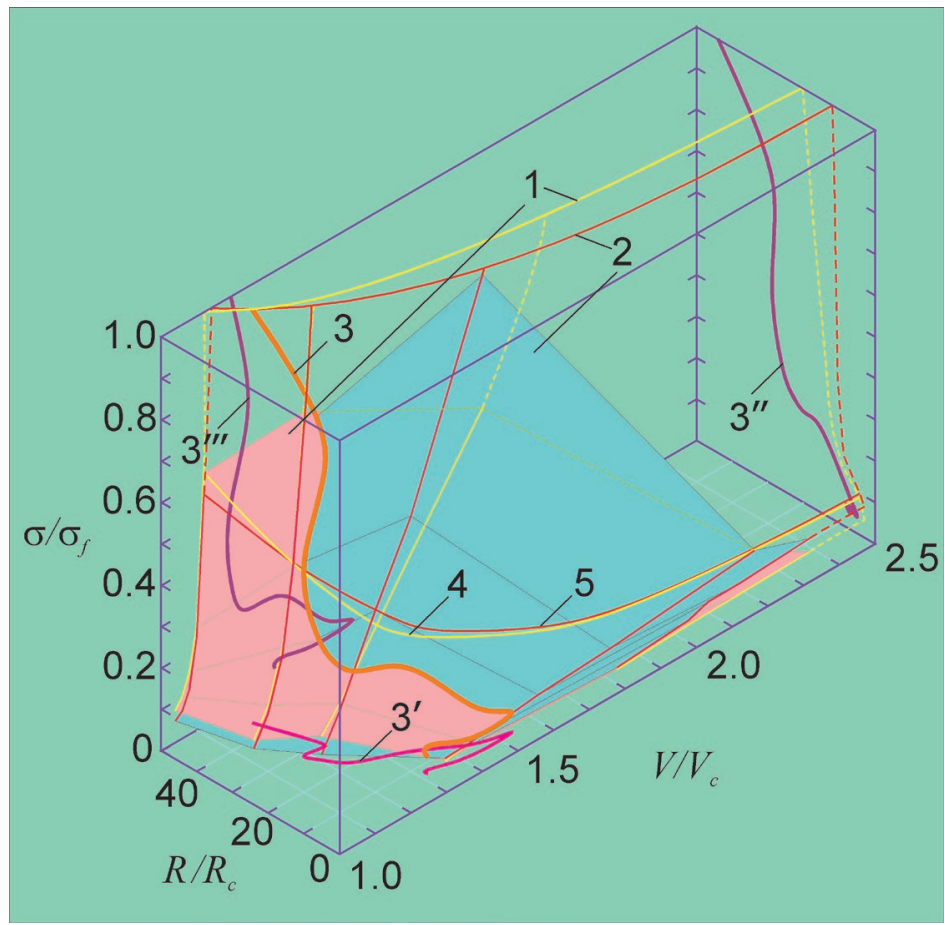

Fig. 4. Surfaces of stress distribution along the axis (surface 1) and closed-loop fixing of anodes (surface 2) as well as their threedimensional intersection curve (3) with its projections on the coordinate planes $\left[\mathrm{R} / \mathrm{R}_{\mathrm{c}}\right.$; $\left.\mathrm{V} / \mathrm{V}_{\mathrm{c}}\right],\left[\sigma / \sigma_{\mathrm{f}} ; \mathrm{R} / \mathrm{R}_{\mathrm{c}}\right]$, and $\left[\sigma / \sigma_{\mathrm{f}} ; \mathrm{V} / \mathrm{V}_{\mathrm{c}}\right]$ (curves 3', 3', , and 3',' respectively).

Curves 4 and 5 (located on surfaces 1 and 2 respectively) show levels of stresses in anodes with a $1 \mathrm{~mm}$ thick cylindrical part and a variety of $\mathrm{R} / \mathrm{R}_{\mathrm{c}}\left(\mathrm{V} / \mathrm{V}_{\mathrm{c}}\right)$ ratios

Curve 3" for the ranges $0.065<\left(\sigma / \sigma_{f}\right)<0.430$ and $7.5<\left(R / R_{c}\right)<22$ was described by an equation:

$$
\sigma / \sigma_{f}=0.000022 \cdot\left(R / R_{c}\right)^{4}-0.00126 \cdot\left(R / R_{c}\right)^{3}+0.0275 \cdot\left(R / R_{c}\right)^{2}-0.2454 \cdot\left(R / R_{c}\right)+0.7774 .
$$




\section{Ihor Kuzio, Bogdan Vasyliv, Vitaliy Korendiy, Volodymyr Borovets, Viktoriya Podhurska} equation:

Curve 3" "for the ranges $0.065<\left(\sigma / \sigma_{f}\right)<0.280$ and $1.20<\left(V / V_{c}\right)<1.47$ was described by an

$$
\sigma / \sigma_{f}=549.26 \cdot\left(V / V_{c}\right)^{4}-2961.15 \cdot\left(V / V_{c}\right)^{3}+5973.1 \cdot\left(V / V_{c}\right)^{2}-5343.51 \cdot\left(V / V_{c}\right)+1789.15 .
$$

Based on the equations (1) and (3) for the volumes of the cylindrical and spheroidal shape anodes as well as their ratios it can be noted that for a certain $R / R_{c}$ ratio range (approximately from 3 to 50) curve 3, for anodes with a radius of the cylindrical part $R_{c}>12 \mathrm{~mm}$ (see Fig. 4) will be shifted towards lower values of $V / V_{c}$ while curve 3" will be shifted towards higher values of $\sigma / \sigma_{f}$, and curve 3", will be shifted towards lower values of $V / V_{c}$ and higher values of $\sigma / \sigma_{f}$.

Thus, a spheroidal shape anode allows the stress distribution to be changed and a level of maximum strain in a fuel cell to be lowered. Therefore, it allows resistance to its deformation, and the lifetime of a fuel cell to be increased. This reduces the cost of electricity that the cell produces, and thus increases the efficiency of a solid oxide fuel cell with an anode-substrate of spheroidal shape as compared to the fuel cell comprising an anode-substrate of the cylindrical shape.

In order to evaluate crack growth resistance of SOFC anode-substrate of a certain shape, a shapedependent crack deceleration approach [16] was used. Diagrams (Fig. 5) of the crack initiated at the edge of an anode-substrate with (a) parallel working surfaces (the profile angle $\theta=0$ ) and (b) convex ones $(\theta>0)$ allow modeling crack growth in both the profiles using corresponding parameters of geometry and load.
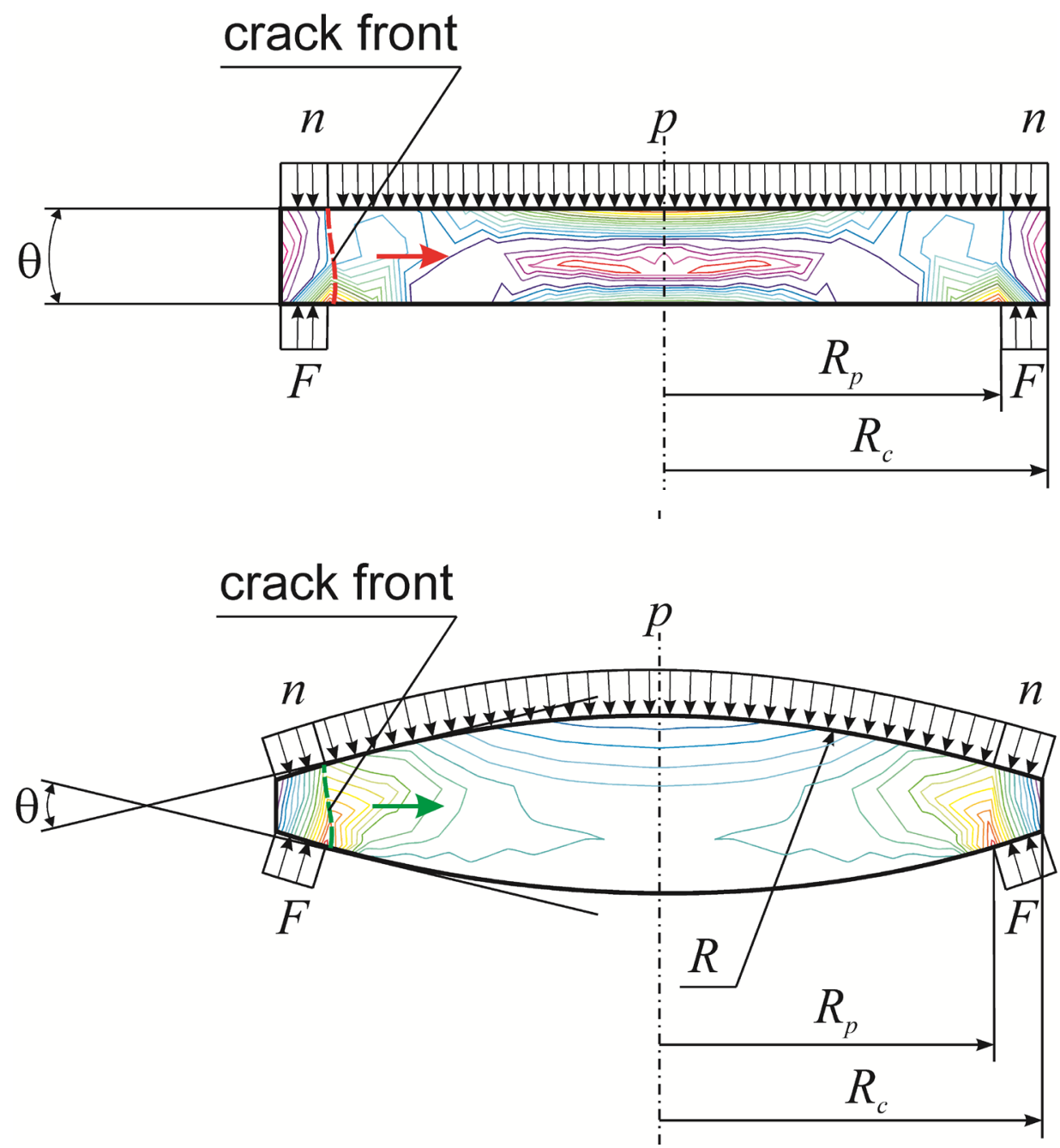

Fig. 5. Diagrams of the crack initiated at the edge of an anode-substrate with (a) parallel working surfaces (the profile angle $\theta=0)$ and (b) convex ones $(\theta>0)$. Notation is the same as in Fig. 1 . A dashed line marks the crack front, and a horizontal arrow indicates the direction of crack advance for each case 


\section{Substantiation of the Shape of a Solid Oxide Fuel Cell Anode using the Stress-Strain and ...}

If accidentally, a crack is initiated at the edge of an anode, it may advance depending on the crack profile geometry and loading conditions. One can evaluate the stress intensity factor $K$ at the crack tip depending on the loading mode. For the case of the external gas pressure $p=1 \mathrm{MPa}$ and fixing pressure $n=1 \mathrm{MPa}$ applied to the cylindrical shape anode of radius $12 \mathrm{~mm}$ and thickness $1 \mathrm{~mm}$ (see Fig. 5) we assume that these forces cause $K_{\text {III }}$ mode of crack growth (tearing or out-of-plane shear mode), and this parameter can be defined using approximate correlation between $K_{\mathrm{I}}$ and $K_{\mathrm{III}}$ modes as $K_{\mathrm{III}}=\alpha K_{\mathrm{I}}$, where $\alpha$ is a correlation factor in the range of $0.2-0.6$ [17].

We can use minimum value 0.2 of this factor to estimate ultimate stress arising in the material of an anode at equivalent conditions corresponding $K_{\mathrm{I}}$ mode:

$$
\begin{gathered}
K_{\mathrm{I}}=\frac{K_{\mathrm{III}}}{\alpha} \text { or } \sigma_{u}=\frac{p+n}{\alpha}, \\
\text { i.e., } \sigma_{u}=\frac{1+1}{0.2}=10 \mathrm{MPa} .
\end{gathered}
$$

In case of a certain crack length $a=1.5 \mathrm{~mm}$ we can calculate an equivalent value of $K_{\mathrm{I}}$ using a conventional formula [18] for eccentric tension of a compact precracked specimen with straight-through notch:

$$
\begin{gathered}
K_{\mathrm{I}}=\sigma_{u} \cdot \sqrt{\pi \cdot a}, \\
\text { i.e., } K_{\mathrm{I}}=10 \cdot \sqrt{\pi \cdot 1.5 \cdot 0.001}=0.7 \mathrm{MPa} \cdot \mathrm{m}^{1 / 2} .
\end{gathered}
$$

Taking into account a range of the fracture toughness $K_{\text {Ic }}$ of $1.9-3.4 \mathrm{MPa}^{1 / 2}$ for the YSZ-Ni cermet presented in [1] we can conclude that calculated above the value of $K_{\text {I }}$ parameter does not reach this range. That is, an initiated crack may advance subcritically at these conditions [16].

Similarly to the cylindrical shape anode, we can estimate crack growth behavior in a spheroidal shape anode. For the last having similar crack initiated at the edge, conditions of crack growth also depend on its profile and applied load. In particular, the same $K_{\text {III }}$ value (corresponding to an equivalent value of $K_{\mathrm{I}}$ ) is reached when a crack approaches the length of crack front $1 \mathrm{~mm}$, i.e. values of the crack front length become the same for both the cylindrical and spheroidal shape anodes.

But in the case of spheroidal shape anode, a crack is already decelerated if the current value of the crack profile angle is about 10 degrees [16].

In order to study a process of crack retardation in detail, its behaviour was modelled using various $R / R_{\mathrm{c}}$ ratio, namely $3,5,15$, and 20 (at constant $R_{\mathrm{c}}=12 \mathrm{~mm}$ ), which allows constructing anode-substrates of four various shapes with convex working surfaces. Circumscribed figures were also drawn outside these shapes. Such modelling figures are rectangle ones with symmetrical chevron cross-sections having the profile angle $\theta$ of $41.2^{\circ}, 25.26^{\circ}, 9.56^{\circ}$, and $7.55^{\circ}$ respectively (Fig. 6a). These profile angles correspond to the initial ones measured for the four various shapes.

The stress intensity factor $K_{\mathrm{CN}}$ at the crack tip in a chevron specimen can be determined as follows [16]:

$$
K_{\mathrm{CN}}=\frac{P_{x}}{B} \cdot \sqrt{\frac{\pi}{W}} \cdot y_{\mathrm{STC}} \cdot\left(\frac{\alpha_{1}-\alpha_{0}}{\alpha-\alpha_{0}}\right)^{0.5},
$$

where $P_{\mathrm{x}}$ is the applied tensile load, $B$ and $W$ are the thickness and width of a specimen respectively, $a_{1}$ is the distance from load line to the point where chevron notch intersects specimen surface, $\alpha_{1}=a_{1} / W, a_{0}$ is the distance from load line to the tip of chevron notch, $\alpha_{0}=a_{0} / W, a$ is the crack length, $\alpha=a / W$ is the relative crack length;

$$
y_{\mathrm{STC}}=16.7 \alpha^{1 / 2}-104.7 \alpha^{3 / 2}+369.9 \alpha^{5 / 2}-573.8 \alpha^{7 / 2}+360.5 \alpha^{9 / 2} \text {. }
$$

The crack running load $P_{\mathrm{x}}$ applied to a specimen with symmetrical chevron crack profile was determined by transforming Eq. (11): 


$$
P_{\mathrm{X}}=\frac{K_{\mathrm{CN}} \cdot B \cdot \sqrt{W}}{y_{\mathrm{STC}} \cdot \sqrt{\pi}} \cdot\left(\frac{\alpha_{1}-\alpha_{0}}{\alpha-\alpha_{0}}\right)^{-0.5} .
$$
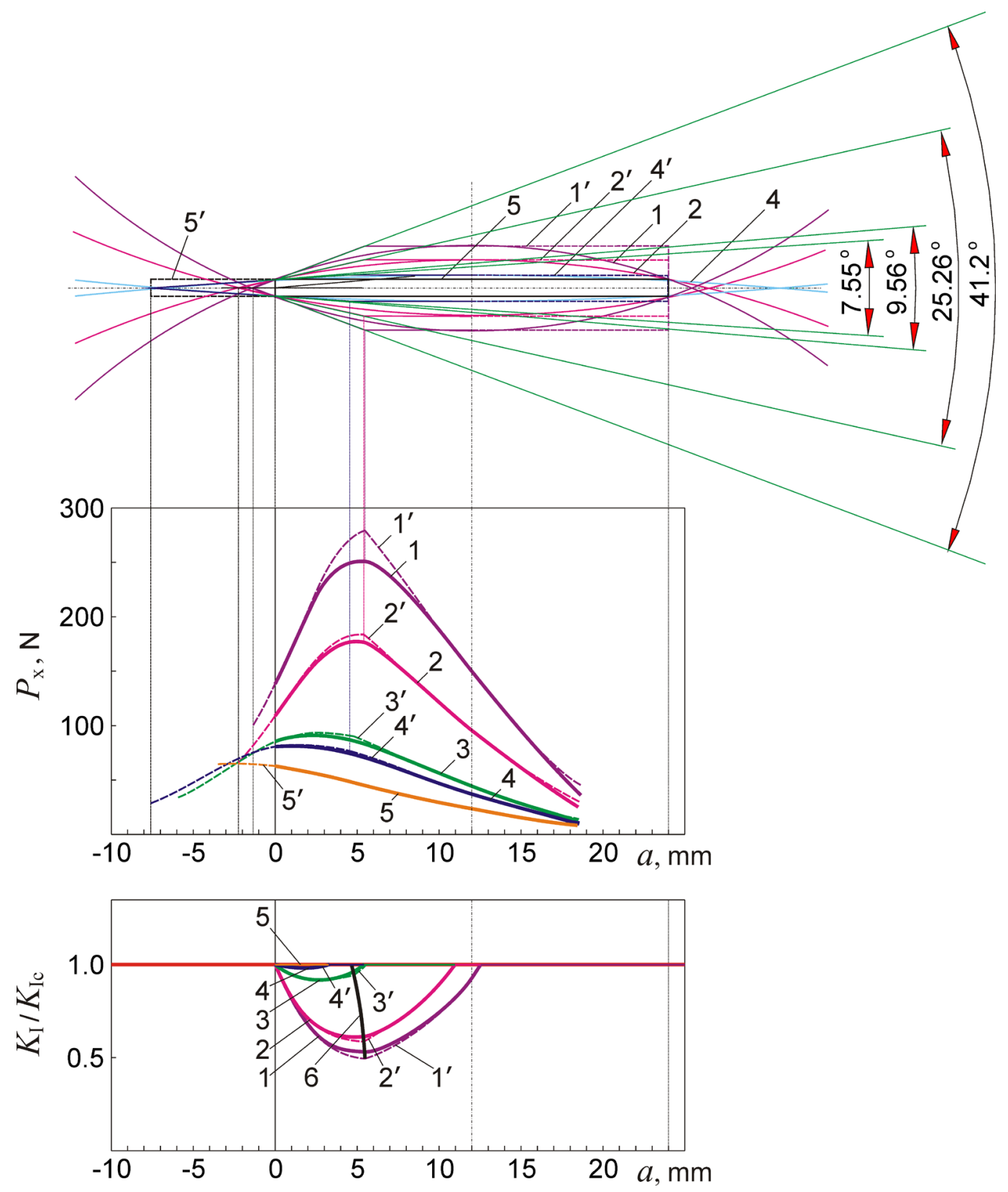

Fig. 6. Diagrams of (a) anode-substrates with cracks of a certain length of their fronts, and corresponding dependences of (b) the crack running load, $\mathrm{P}_{\mathrm{x}}$, vs the crack length, a, and (c) the stress intensity factor ratio, $\mathrm{K}_{\mathrm{I}} / \mathrm{K}_{\mathrm{Ic}}$, vs the crack length, a. The positions 1-4 (solid lines) correspond to the anodes with convex working surfaces, with the initial profile angle $\theta$ of $41.2^{\circ}, 25.26^{\circ}, 9.56^{\circ}$, and $7.55^{\circ}$ respectively, and parallel working surfaces $(\theta=0$, position 5 , solid lines). The positions 1' $-5^{\prime}$ (dashed lines) correspond to circumscribed figures drawn outside mentioned above

shapes. Curve 6 marks the boundary positions where corresponding cracks put out of the chevron profiles. A horizontal line (c) marks the start value of $\mathrm{K}_{\mathrm{I}} / \mathrm{K}_{\mathrm{Ic}}$ ratio equal to 1 , which corresponds to certain start values of $\mathrm{P}_{\mathrm{x}}$ (b).

The stress intensity factor ratio, $\mathrm{K}_{\mathrm{I}} / \mathrm{K}_{\mathrm{Ic}}$, vs the crack length, a, dependences (c) are plotted at $\mathrm{P}_{\mathrm{x}}=$ const for corresponding shapes

Having calculated values of $P_{\mathrm{x}}$ for the four profile angles, we constructed the crack running load, $P_{\mathrm{x}}$, vs the crack length, $a$, dependences (Fig. 6b) for the modeling figures (dashed lines) with cracks of a 


\section{Substantiation of the Shape of a Solid Oxide Fuel Cell Anode using the Stress-Strain and ...}

certain length of their fronts (Fig. 6a).

Then, the stress intensity factor ratio, $K_{\mathrm{I}} / K_{\mathrm{Ic}}$, vs the crack length, $a$, dependences (Fig. 6c) were plotted at $P_{\mathrm{x}}=$ const for corresponding shapes pointed out above, starting from a value $K_{\mathrm{I}} / K_{\mathrm{Ic}}=1$ which corresponds to certain start values of $P_{\mathrm{x}}$ (Fig. 6b).

Also, approximated curves for actual anode-substrate shapes (Fig. 6b, c) were constructed (solid lines) which allow predicting behavior of an initiated crack in such products. Curve 6 (Fig. 6c) marks the boundary positions where corresponding cracks put out of the chevron profiles. It can be noted that the curves for the actual shapes differ slightly from ones for the modeling figures.

When studying crack behavior at the start value of $K_{\mathrm{I}} / K_{\mathrm{Ic}}$ equal to 0.37 (a particular case described above, $K_{\mathrm{Ic}}=0.7 \mathrm{MPam}^{1 / 2}$ ) one can note general tendencies of the curves for corresponding profiles (Fig. 7).

Based on Figs. 6 and 7 it can be concluded that in the case of a spheroidal shape anode, crack retardation occurs when the current value of the crack profile angle is about 10 degrees (Fig. 6c, curve 3) or more.

So the spheroid shaped SOFC anode-substrate has a higher resistance to crack advance as compared to a conventional flat one.

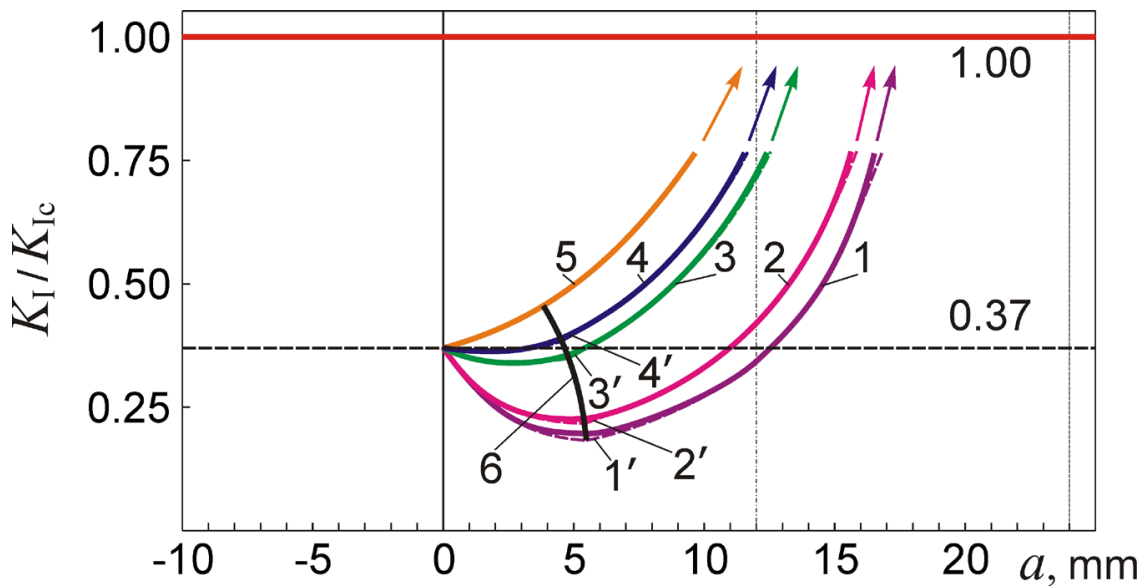

Fig. 7. The stress intensity factor ratio, $\mathrm{K}_{\mathrm{I}} / \mathrm{K}_{\mathrm{Ic}}$, vs the crack length, a, dependences for anode-substrates of various shapes (notation is the same as in Fig. 6). A horizontal dashed line marks the start value of $\mathrm{K}_{\mathrm{I}} / \mathrm{K}_{\mathrm{Ic}}$ ratio, and arrows indicate the tendencies of its change while $\mathrm{P}_{\mathrm{x}}=$ const for corresponding shapes

Thus, a shape-dependent crack deceleration approach is a successful tool for evaluation of the resistance to crack advance in the SOFC anode-substrate of various shapes.

\section{Conclusions}

In this work, the improved shape of an anode-substrate for a solid oxide fuel cell has been suggested. Using the finite element analysis the stress and strain distributions in YSZ-NiO anodes of the cylindrical and spheroidal shapes were calculated. Based on the calculations, dimensions and their ratios ranges were defined which correspond to improved stress and strain characteristics of an anode. According to this, an anode of the cylindrical shape with top and bottom convex surfaces (a spheroidal shape anode), with $R / R_{c}$ ratio in the range from 5 to 20 is suggested. Its specific volume $V / S_{c}$ is in the range from 1 to $2.5 \mathrm{~mm}$. The stresses in the most dangerous areas (i. e. along the axis and the closed-loop fixing) and maximum strain, caused by external gas pressure on the anode working surface, are decreased by $10-30 \%$ and $20-40 \%$ respectively as compared to an anode of the cylindrical shape of the same radius and volume features. This increases the lifetime of a solid oxide fuel cell. A three-dimensional curve of intersection of the surfaces of stress distribution in the anode along its axis and the closed-loop fixing was approximated which displays the values of balanced stresses depending on $V / V_{c}$ and $R / R_{c}$ parameters. The advantage of the spheroid shaped SOFC anode-substrate over conventional flat one was substantiated using a shape-dependent crack deceleration approach. 


\section{Ihor Kuzio, Bogdan Vasyliv, Vitaliy Korendiy, Volodymyr Borovets, Viktoriya Podhurska}

\section{References}

[1] M. Radovic, and E. Lara-Curzio, "Mechanical properties of tape cast nickel-based anode materials for solid oxide fuel cells before and after reduction in hydrogen", Acta Mater., vol. 52, pp. 5747-5756, Jul. 2004.

[2] B. D. Vasyliv et al., "Sposib obrobky NiO-vmisnykh anodiv tverdooksydnoi palyvnoi komirky" ["A method of treatment of NiO-containing anodes for a solid oxide fuel cell"], UA Patent 78992, April 10, 2013. [in Ukrainian].

[3] Y. Wang, et al., "Effects of powder sizes and reduction parameters on the strength of Ni-YSZ anodes", Solid State Ionics, vol. 177, pp. 1517-1527, Oct. 2006.

[4] B. D. Vasyliv, "A procedure for the investigation of mechanical and physical properties of ceramics under the conditions of biaxial bending of a disk specimen according to the ring-ring scheme", Mater. Sci., vol. 45, issue 4, pp. 571-575, Jul. 2009.

[5] B. D. Vasyliv, "Improvement of the electrical conductivity of the material of anode in a fuel cell by the cyclic redox thermal treatment", Mater. Sci., vol. 46, issue 2, pp. 260-264, Nov. 2010.

[6] A. Wood, and D. Waldbillig, "Preconditioning treatment to enhance redox tolerance of solid oxide fuel cells", U.S. Patent 8029946 B2, October 04, 2011.

[7] V. Ya. Podhurs'ka, et al., "Structural transformations in the NiO-containing anode of ceramic fuel cells in the course of its reduction and oxidation”, Mater. Sci., vol. 49, issue 6, pp. 805-811, May 2014.

[8] V. Podhurska, et al., "Influence of treatment temperature on microstructure and properties of YSZ-NiO anode materials", Nanoscale Res. Lett., 11:93, Febr. 2016.

[9] B. Vasyliv, et al., "Preconditioning of the YSZ-NiO fuel cell anode in hydrogenous atmospheres containing water vapor", Nanoscale Res. Lett., 12:265, Apr. 2017.

[10] R.-H. Song, D.-R. Shin, and J.-H. Kim, "Anode-supported flat-tubular solid oxide fuel cell stack and fabrication method of the same", U.S. Patent 7285347 B2, October 23, 2007.

[11] Y. Bai, et al., "Dip coating technique in fabrication of cone-shaped anode-supported solid oxide fuel cells", J. Alloys and Compounds, vol. 480, pp. 554-557, Sept. 2009.

[12] Y. Zhang, et al., "Redox cycling of Ni-YSZ anode investigated by TRP technique", Solid State Ionics, vol. 176, pp. 2193-2199, Nov. 2005.

[13] B. Sun, et al., "Effect of thermal cycling on residual stress and curvature of anode-supported SOFCs", Fuel Cells, vol. 6, pp. 805-813, Jul. 2009.

[14] T. Miyazawa, "Flat-plate solid oxide fuel cell", U.S. Patent 20110091785 A1, April 21, 2011.

[15] O. P. Ostash, B. D. Vasyliv, and V. Ya. Podhurska, "Sposib vyhotovlennia anoda-pidkladky dlia palyvnoi komirky" ["A method of fabrication of an anode substrate for a fuel cell"], UA Patent 109256, August 25, 2016. [in Ukrainian].

[16] B. Vasyliv, Crack initiation and retardation in ceramics. Techniques and applications. Riga, Latvia: LAP LAMBERT Academic Publishing, 2019.

[17] L. Pook, "The fatigue crack direction and threshold behavior of mild steel under mixed mode I and III loading”, Int. Journal of Fatigue, vol. 7, issue 1, pp. 21-30, Febr. 1985.

[18] Stress analysis of cracks, ASTM STP 381, 1965. 